\title{
Predictors of success for combined endoscopic third ventriculostomy and choroid plexus cauterization in a North American setting: a Hydrocephalus Clinical Research Network study
}

\author{
Jay Riva-Cambrin, MD, MSc, ${ }^{1}$ John R. W. Kestle, MD, MSc, ${ }^{2}$ Curtis J. Rozzelle, MD, ${ }^{3}$ \\ Robert P. Naftel, MD, ${ }^{4}$ Jessica S. Alvey, MSc, ${ }^{2}$ Ron W. Reeder, PhD, ${ }^{2}$ Richard Holubkov, PhD, ${ }^{2}$ \\ Samuel R. Browd, MD, PhD, ${ }^{5}$ D. Douglas Cochrane, MD, ${ }^{6}$ David D. Limbrick Jr., MD, PhD, ${ }^{7}$ \\ Chevis N. Shannon, DrPH, ${ }^{4}$ Tamara D. Simon, MD, MSPH, ${ }^{5}$ Mandeep S. Tamber, MD, PhD, ${ }^{8}$ \\ John C. Wellons III, MD, MSPH, William E. Whitehead, MD, MSc, ${ }^{9}$ and \\ Abhaya V. Kulkarni, MD, PhD, ${ }^{7}$ for the Hydrocephalus Clinical Research Network

\begin{abstract}
'Alberta Children's Hospital, University of Calgary, Alberta, Canada; 'University of Utah, Salt Lake City, Utah; ${ }^{3}$ Children's Hospital of Alabama, Birmingham, Alabama; ${ }^{4}$ Vanderbilt University, Nashville, Tennessee; ${ }^{5}$ Seattle Children's Hospital, Seattle, Washington; ${ }^{6}$ Hospital for Sick Children, University of Toronto, Ontario, Canada; ${ }^{7}$ St. Louis Children's Hospital, St. Louis, Missouri; ${ }^{8}$ Pittsburgh Children's Hospital, Pittsburgh, Pennsylvania; and ${ }^{9}$ Texas Children's Hospital, Houston, Texas
\end{abstract}

\begin{abstract}
OBJECTIVE Endoscopic third ventriculostomy combined with choroid plexus cauterization (ETV+CPC) has been adopted by many pediatric neurosurgeons as an alternative to placing shunts in infants with hydrocephalus. However, reported success rates have been highly variable, which may be secondary to patient selection, operative technique, and/or surgeon training. The objective of this prospective multicenter cohort study was to identify independent patient selection, operative technique, or surgical training predictors of ETV+CPC success in infants.
\end{abstract}

METHODS This was a prospective cohort study nested within the Hydrocephalus Clinical Research Network's (HCRN) Core Data Project (registry). All infants under the age of 2 years who underwent a first ETV+CPC between June 2006 and March 2015 from 8 HCRN centers were included. Each patient had a minimum of 6 months of follow-up unless censored by an ETV+CPC failure. Patient and operative risk factors of failure were examined, as well as formal ETV+CPC training, which was defined as traveling to and working with the experienced surgeons at CURE Children's Hospital of Uganda. ETV+CPC failure was defined as the need for repeat ETV, shunting, or death.

RESULTS The study contained 191 patients with a primary ETV+CPC conducted by 17 pediatric neurosurgeons within the HCRN. Infants under 6 months corrected age at the time of ETV+CPC represented $79 \%$ of the cohort. Myelomeningocele $(26 \%)$, intraventricular hemorrhage associated with prematurity $(24 \%)$, and aqueductal stenosis $(17 \%)$ were the most common etiologies. A total of $115(60 \%)$ of the ETV+CPCs were conducted by surgeons after formal training. Overall, ETV+CPC was successful in $48 \%, 46 \%$, and $45 \%$ of infants at 6 months, 1 year, and 18 months, respectively. Young age (<1 month) (adjusted hazard ratio [aHR] 1.9, 95\% Cl 1.0-3.6) and an etiology of post-intraventricular hemorrhage secondary to prematurity (aHR $2.0,95 \% \mathrm{Cl} 1.1-3.6)$ were the only two independent predictors of ETV+CPC failure. Specific subgroups of ages within etiology categories were identified as having higher ETV+CPC success rates. Although training led to more frequent use of the flexible scope $(p<0.001)$ and higher rates of complete $(>90 \%)$ CPC $(p<0.001)$, training itself was not independently associated (aHR 1.1, 95\% Cl 0.7-1.8; $p=0.63$ ) with ETV+CPC success.

CONCLUSIONS This is the largest prospective multicenter North American study to date examining ETV+CPC. Formal ETV+CPC training was not found to be associated with improved procedure outcomes. Specific subgroups of ages within specific hydrocephalus etiologies were identified that may preferentially benefit from ETV+CPC.

https://thejns.org/doi/abs/10.3171/2019.3.PEDS18532

KEYWORDS endoscopic third ventriculostomy combined with choroid plexus cauterization; ETV+CPC; predictors; Hydrocephalus Clinical Research Network; HCRN; hydrocephalus

ABBREVIATIONS aHR = adjusted hazard ratio; CCC = complex chronic condition; CCHU = CURE Children's Hospital of Uganda; DCC = Data Coordinating Center; $\mathrm{ETV}+\mathrm{CPC}=$ endoscopic third ventriculostomy combined with choroid plexus cauterization; ETVSS = ETV Success Score; EVD = external ventricular drain; FOR = frontal/ occipital horn ratio; HCRN = Hydrocephalus Clinical Research Network; IVH = intraventricular hemorrhage.

SUBMITTED August 24, 2018. ACCEPTED March 12, 2019.

INCLUDE WHEN CITING Published online May 31, 2019; DOI: 10.3171/2019.3.PEDS18532. 
I N 2005, Warf published a seminal study, based on his work at CURE Children's Hospital of Uganda (CCHU), describing the use of the endoscopic third ventriculostomy combined with choroid plexus cauterization $(\mathrm{ETV}+\mathrm{CPC})$ for the treatment of hydrocephalus in infants. ${ }^{19}$ This surgical technique continues to grow in popularity in both the African and the North American settings. ${ }^{4}$ One driver for this expansion is the broadening of criteria for patients to be selected for ETV+CPC. In the original publication, $71 \%$ of infants had postinfectious or myelomeningocele etiologies for hydrocephalus. ${ }^{19}$ However, patient selection has evolved to include intraventricular hemorrhage (IVH) secondary to prematurity, ${ }^{3,8,18}$ DandyWalker syndrome, ${ }^{25}$ congenital communicating hydrocephalus, ${ }^{8,20}$ and encephaloceles. ${ }^{21}$

Prior to this current study, the impact of ETV+CPC patient selection on procedural success had not yet been fully elucidated, with recent publications showing divergent results. ${ }^{1,2,8,16,22-24}$ In the North American setting, Stone and Warf published an overall ETV+CPC success rate of 57\% and a $65 \%$ shunt-free rate in 91 infants with hydrocephalus. ${ }^{16}$ Other single-center studies without affiliation with CCHU have reported significantly lower success rates of 37\%-42\%.,23 The Hydrocephalus Clinical Research Network (HCRN) itself has previously published studies demonstrating varying overall ETV+CPC success rates. Originally, the HCRN published a retrospective 7-center study $(\mathrm{n}=36)$ that found a more moderate $52 \%$ overall success rate at 6 months before any formal training relationship with CCHU. ${ }^{8}$ More recently, the HCRN published a 9-center prospective cohort study $(\mathrm{n}=118)$ revealing a significantly lower $36 \%$ overall success rate at 6 months. ${ }^{10}$ Therefore, it remains unclear whether these highly variable ETV+CPC success rates are associated with patient selection, operative technique, and/or surgeon training.

The objective of this prospective cohort study was to identify independent patient selection, operative technique, or surgical training predictors of ETV+CPC success in the infant hydrocephalus population. This HCRN study represents the largest multicenter study of ETV+CPC ever conducted in a North American setting.

\section{Methods \\ Study Population}

The study included all infants (age $<2$ years) treated with an ETV+CPC procedure for hydrocephalus between June 9, 2006, and March 1, 2015, at 8 participating HCRN centers. Included infants could have had an ETV+CPC either as a first procedure after initial diagnosis or secondarily after a failed CSF shunt. No hydrocephalus etiologies were explicitly excluded because the decision to offer $\mathrm{ETV}+\mathrm{CPC}$ was made entirely by the treating pediatric neurosurgeon. The participating centers within the HCRN for this specific study were as follows: the University of Utah/Primary Children's Hospital; the University of Alabama at Birmingham/Children's Hospital of Alabama; the University of Toronto/Hospital for Sick Children; the University of Washington/Seattle Children's Hospital; Baylor College of Medicine/Texas Children's Hospital; the University of Pittsburgh/Children's Hospital of Pittsburgh of the University of Pittsburgh Medical Center; Washington University/St. Louis Children's Hospital; and Vanderbilt University/Monroe Carell Jr. Children's Hospital at Vanderbilt. A minimum of 6 months of follow-up was required for entry into the study.

\section{Data Collection and Management}

The study combined two data sources-a prospective cohort and a retrospective cohort. The majority (96\%) of the 191 infants were recruited via the prospective cohort study nested within the HCRN's Core Data Project or registry. In an attempt to capture every ETV+CPC ever performed at the 8 participating centers and to maximize the heterogeneity of patient selection and surgeon experience, the study cohort was supplemented by the addition of 8 (4\%) infants not originally enrolled within this prospective study (i.e., ETV+CPC before the inception of the prospective study/registry). Therefore, all 36 of the patients from Kulkarni et al. for the HCRN (2014) are represented in this study -8 fully abstracted retrospectively and 28 who were prospectively enrolled in this nested registry study but supplemented with retrospective data collection of CPC details. ${ }^{8}$ This patient cohort predated and was completely exclusive of the HCRN's recently published prospective cohort study. ${ }^{15}$

The study was approved by the institutional review board or research ethics board at each participating site as well as for the Data Coordinating Center (DCC) at the University of Utah. A waiver of consent was granted for the DCC and 6 centers, whereas 2 study sites required patient/parental informed consent before enrollment in the Core Data Project. For the prospective cohort, data were collected by a dedicated HCRN research coordinator in the operating room, clinic, and ward settings. For the retrospective cohort, data were abstracted from electronic and paper patient medical charts and imaging records. ${ }^{8}$ De-identified data were then uploaded to a secure server at the DCC and were systematically queried for data quality.

\section{Patient Selection Variables}

Patient age at ETV+CPC surgery was presented as corrected age after 40 weeks' gestation to adjust for premature birth, and was reported in months (categorically) and weeks (continuously). Corrected age was categorized into $<1$ month, $1-5$ months, $6-11$ months, and $\geq 1$ year to be consistent with the ETV Success Score (ETVSS) and previous publications. ${ }^{9,10}$ Hydrocephalus etiology was assigned prospectively (in the prospective cohort) by the treating surgeon into one of 16 etiologies previously described by the HCRN..$^{13}$ In the retrospective cohort, etiology was assigned via review of the neurosurgical medical record and imaging. For meaningful analysis, these etiologies were collapsed into the most prevalent categories-myelomeningocele, post-IVH secondary to prematurity, aqueductal stenosis, and other. Comorbidities were collected using the pediatric complex chronic condition (CCC) methodology ${ }^{5}$ excluding hydrocephalus. ${ }^{13,14}$ The ventricle size at the last imaging (CT or MRI) before ETV+CPC was measured using the frontal/occipital horn ratio (FOR). ${ }^{11}$ Midline sagittal series of these images were also examined to deter- 
mine whether the floor of the third ventricle was normal or concave. Sex, race, insurance classification, ETVSS, and head circumference percentile corrected for age were also collected.

\section{Operative Technique Variables}

Duration of surgery was recorded in minutes and was defined as the time between the first incision and final skin closure. Surgical priority (elective, add-on, or emergency) was recorded per the actual booking by the attending surgeon. The percentage of CPC of the lateral ventricles was grossly estimated by the surgeon in a nonvalidated manner and dichotomized into $>90 \%$ and $\leq 90 \%{ }^{8}$ The "use of navigation" variable included either intraoperative ultrasound or frameless stereotaxy, primarily for entrance into the lateral ventricle. Procedures were deemed to be abandoned when the neurosurgeon did not complete the ETV or attempt any CPC, either due to anatomical considerations or secondary to complications such as hemorrhage. Other operative variables that were collected included whether the floor of the third ventricle ballooned up after ventriculostomy creation, presence of residual (i.e., unfenestrated) membranes in the prepontine cistern, an associated biopsy, the use of the flexible versus the rigid endoscope, whether the scope was guided through the ventriculostomy, whether a "naked" basilar artery was observed beneath the ventriculostomy, ${ }^{9}$ the surgeon's estimate of the final size of the ventriculostomy in millimeters, and whether an external ventricular drain (EVD) was left after the procedure.

Complications were collected in a standardized fashion and divided into surgical complications (e.g., new neurological deficits, procedure-related hemorrhage, CSF leaks) and medical complications (e.g., hyponatremia, pneumonia). These were further divided into two timing categories, including those complications occurring in the immediate inpatient setting before discharge, and those occurring in a delayed fashion in individuals who were outpatients after hospital discharge.

\section{"Formally Trained" Versus "Formally Untrained" ETV+CPC}

Each ETV+CPC procedure was dichotomized into either a so-called formally trained or a formally untrained procedure. A formally trained procedure was defined as one conducted by a pediatric neurosurgeon who, before the procedure, had traveled to CCHU in Mbale, Uganda, and had formally trained with this group specifically for ETV+CPC. Formally untrained procedures were those conducted by pediatric neurosurgeons who, at the time of the procedure, had not traveled for training at CCHU. This included surgeons who had never traveled to CCHU or surgeons performing procedures before their training at $\mathrm{CCHU}$.

Formal training at CCHU consisted of a 1-week visit with active participation in all aspects of the perioperative management of infant hydrocephalus, including ETV+CPC intraoperative technique. All surgeons obtained Ugandan medical licenses to allow them to fully participate in all phases of care. During the week of train- ing, each surgeon performed at least $10 \mathrm{ETV}+\mathrm{CPC}$ procedures.

\section{Study Outcomes}

The primary outcome of this study was time to $\mathrm{ETV}+\mathrm{CPC}$ failure. $\mathrm{ETV}+\mathrm{CPC}$ failure was defined as patient death, ETV+CPC abandonment, or the need for a subsequent CSF diversion surgery including the placement of a CSF shunt or an ETV revision. All ETV+CPC survival data were censored on May 31, 2015, for analysis. The data were also analyzed using formally trained versus formally untrained ETV+CPC procedures as a secondary outcome to determine whether there were significant differences in patient selection or surgical techniques associated with formal training at CCHU.

\section{Statistical Analyses}

Continuous variables were reported as means \pm SDs except for corrected age in weeks, which was reported as a median with minimum and maximum values. Categorical variables were reported as frequencies and percentages. Patient selection and operative technique variables (see Table 3) were compared with the primary outcome of time to ETV+CPC failure by using univariable Cox proportional hazards modeling. Significant $(\mathrm{p}<0.05$ : corrected age, etiology, and FOR) and near-significant ( $p<0.10$ : training and use of the flexible scope) variables were included in the multivariable Cox proportional hazards model. Significant (and near-significant) variables identified by the multivariable modeling were reported as the hazard ratio (HR) with 95\% confidence intervals (CIs). No violations of the proportional hazards assumptions were found.

We then used the two variables that were found to have independent and significant (and near-significant) associations with ETV+CPC failure (age and etiology categories) to identify specific patient groups with the highest probability for ETV+CPC success. Therefore, Kaplan-Meier curves were generated for each collapsed etiology category (myelomeningocele, post-IVH secondary to prematurity, aqueductal stenosis, and other), which were stratified by age category.

The secondary analyses comparing formally trained and formally untrained procedures consisted of Student t-tests for continuous variables and Mantel-Haenszel chisquare and Fisher's exact tests for categorical variables. All analyses were conducted by SAS (version 9.4, SAS Institute).

\section{Results}

We enrolled 191 infants with hydrocephalus into the study; these patients had undergone a first ETV+CPC conducted by one of 17 pediatric neurosurgeons at 8 participating centers. Figure 1 demonstrates the rapid escalation of ETV+CPC within the HCRN, especially since 2011. A total of 167 of the ETV+CPCs were first CSF diversion procedures, and 24 followed a shunt failure. A total of $183(96 \%)$ patients were enrolled prospectively and 8 (4\%) were captured retrospectively. The median corrected age at the time of the procedure was 6.3 weeks, but ranged from -6.6 to 92.7 weeks old at ETV+CPC (Table 1). There 


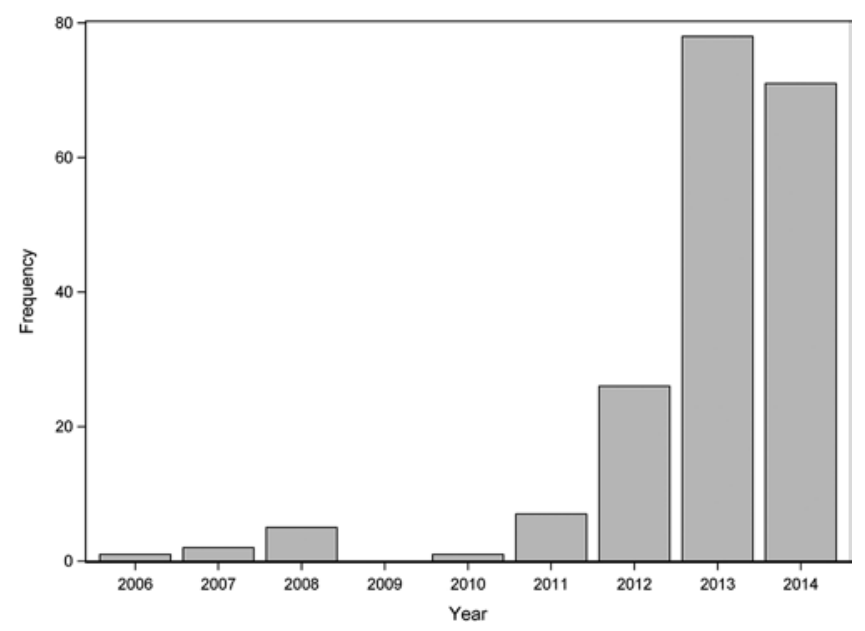

FIG. 1. A histogram demonstrating the incidence of ETV+CPCs conducted within the HCRN by year of study.

was a predominance of males $(65 \%)$ in the cohort, and $46 \%$ had a CCC other than hydrocephalus. The most common hydrocephalus etiologies were myelomeningocele (26\%), post-IVH secondary to prematurity (24\%), aqueductal stenosis (17\%), spontaneous intracranial hemorrhage (7\%), congenital communicating hydrocephalus $(6 \%)$, and a variety of others including postinfectious and intracranial cysts. In terms of imaging, the mean FOR was 0.59 , representing severe ventriculomegaly. ${ }^{6}$

The mean duration of the ETV+CPC procedure was 107 minutes and ranged from 40 to 299 minutes. Sixty percent of procedures were done following formal training, $73 \%$ using the flexible endoscope, and $73 \%$ reported $>90 \%$ CPC (Table 2).

Combining age, etiology, and prior shunting, the cohort had a mean ETVSS $^{7}$ of 46 , compared with a $48 \%$ success rate at 6 months. Overall, ETV+CPC was successful in $48 \%, 46 \%, 45 \%$, and $44 \%$ of infants at 6 months, 1 year, 18 months, and 2 years, respectively. In terms of follow-up, all patients had follow-up at 6 months, $79 \%$ at 12 months, $57 \%$ at 18 months, and $33 \%$ at 2 years.

\section{Univariable Associations With ETV+CPC Failure}

Table 3 demonstrates each clinical and operative variable tested univariably versus the primary outcome of time to ETV+CPC failure. Corrected age category was significantly associated with time to ETV+CPC failure (p $=0.026)$. Infants $1-5$ months of age (HR $1.6,95 \%$ CI $0.9-$ 3.0) and those $<1$ month of age (HR 1.9, 95\% CI 1.1-3.6) had a trend toward and a significantly higher hazard of ETV+CPC failure, respectively (Fig. 2). Greater preoperative ventricle size (i.e., FOR) (HR 6.9, 95\% CI 1.3-37.9; p $=0.027)$ and hydrocephalus etiology $(\mathrm{p}=0.001)$ were also univariably associated with time to ETV+CPC failure. Specifically, patients with the post-IVH secondary to prematurity etiology had much higher ETV+CPC failure (HR 2.3,95\% CI 1.3-4.2) (Fig. 3). The use of the flexible scope (HR 1.5, 95\% CI 0.9-2.4; $\mathrm{p}=0.095$ ) and formally trained procedures (HR 1.4, 95\% CI 0.9-2.1; $\mathrm{p}=0.089$ ) were associated with a trend toward ETV+CPC failure. A high degree $(>90 \%)$ of CPC, residual prepontine membranes,
TABLE 1. Overall description of the patient selection variables within the HCRN's ETV+CPC cohort

\begin{tabular}{|c|c|}
\hline Patient Selection Variables & $\begin{array}{c}\text { Study Cohort, } \\
n=191\end{array}$ \\
\hline \multicolumn{2}{|l|}{ Corrected age } \\
\hline$<1 \mathrm{mo}$ & $86(45.0)$ \\
\hline $1-5$ mos & $64(33.5)$ \\
\hline $6-11 \mathrm{mos}$ & $30(15.7)$ \\
\hline$\geq 1 \mathrm{yr}$ & $11(5.8)$ \\
\hline Median corrected age in wks; min, $\max$ & $6.3 ;-6.6,92.7$ \\
\hline Male sex & $125(65.4)$ \\
\hline \multicolumn{2}{|l|}{ Race } \\
\hline Asian & $2(1.0)$ \\
\hline Black or African American & $33(17.3)$ \\
\hline White & $137(71.7)$ \\
\hline Other/unknown & $19(9.9)$ \\
\hline \multicolumn{2}{|l|}{ Primary payer } \\
\hline Public & $95(49.7)$ \\
\hline Private & $87(45.5)$ \\
\hline Other & $9(4.7)$ \\
\hline \multicolumn{2}{|l|}{ Etiology } \\
\hline Postinfectious & $8(4.2)$ \\
\hline Post-IVH secondary to prematurity & $46(24.1)$ \\
\hline Myelomeningocele & $49(25.7)$ \\
\hline Aqueductal stenosis & $33(17.3)$ \\
\hline Spontaneous ICH & $14(7.3)$ \\
\hline Tumors & $5(2.6)$ \\
\hline Post-head injury & $3(1.6)$ \\
\hline Encephalocele & $1(0.5)$ \\
\hline Posterior fossa cysts & $5(2.6)$ \\
\hline Other intracranial cysts & $6(3.1)$ \\
\hline Congenital communicating hydrocephalus & $11(5.8)$ \\
\hline Other congenital; e.g., holoprosencephaly & $2(1.0)$ \\
\hline Craniosynostosis & $2(1.0)$ \\
\hline Other & $6(3.1)$ \\
\hline$\geq 1 \mathrm{CCC}$ & $87(45.5)$ \\
\hline Cardiac CCC & $34(17.8)$ \\
\hline Head circumference \%ile, mean \pm SD* & $84.5 \pm 28.4$ \\
\hline FOR, mean \pm SD $\dagger$ & $0.59 \pm 0.11$ \\
\hline \multicolumn{2}{|l|}{ Shape of 3rd ventricle floor } \\
\hline Normal & $91(47.6)$ \\
\hline Concave; down & $47(24.6)$ \\
\hline Not available & $53(27.7)$ \\
\hline ETVSS, mean \pm SD & $46.1 \pm 13.9$ \\
\hline
\end{tabular}

$\mathrm{ICH}=$ intracranial hemorrhage; $\max =$ maximum; $\min =$ minimum.

Unless otherwise indicated, values are expressed as the number of patients (\%).

* Based on 162 patients with recorded head circumference.

† Based on 189 patients with suitable imaging.

and ventricle size did not have an association with time to ETV+CPC failure. The HCRN previously found that a cardiac comorbidity was associated with time to shunt failure. ${ }^{14}$ However, this association was not identified in 
TABLE 2. Overall description of the operative technique variables within the HCRN's ETV+CPC cohort

\begin{tabular}{lc}
\hline \multicolumn{1}{c}{ Operative Technique Variables } & Study Cohort, $n=191$ \\
\hline Duration of op in mins, mean \pm SD* $^{*}$ & $106.9 \pm 39$ \\
\hline Surgical priority & $140(73.3)$ \\
\hline Elective & $46(24.1)$ \\
\hline Add-on & $5(2.6)$ \\
\hline Emergency & $115(60.2)$ \\
\hline Conducted by trained surgeon & $140(73.3)$ \\
\hline Flexible scope & $140(73.3)$ \\
\hline$>90 \%$ of CPC & $62(32.5)$ \\
\hline Use of navigation & $0(0)$ \\
\hline Biopsy during same op & $1(0.5)$ \\
\hline Abandoned procedure & $161(85.2)$ \\
\hline Ballooning of floor of 3rd ventricle $\dagger$ & $32(16.9)$ \\
\hline Residual prepontine membranes $\dagger$ & $178(93.7)$ \\
\hline Endoscope guided through ventriculostomy $\ddagger$ & $174(91.6)$ \\
\hline Naked basilar view $\ddagger$ & $4.9 \pm 1.3$ \\
\hline Size of ventriculostomy in mm, mean \pm SD $\dagger$ & $14(7.4)$ \\
\hline EVD inserted $\ddagger$ & \\
\hline Unless otherwise indicated, values are expressed as the number of patients (\%). \\
* Based on $n=185 ; 6$ patients had missing data. \\
$\dagger$ Based on $n=189 ; 2$ patients had missing data. \\
$\ddagger$ Based on $n=190 ; 1$ patient had missing data. \\
\hline
\end{tabular}

the current study's ETV+CPC sample ( $\mathrm{p}=0.79)$, despite a higher incidence of both overall comorbidities $(46 \%$ vs $30 \%)$ and specifically a cardiac comorbidity (18\% vs $8 \%)$.

\section{Multivariable Associations With ETV+CPC Failure}

Significant (corrected age, preoperative FOR, and etiology) and near-significant (formally trained vs formally untrained procedures and the use of the flexible scope) variables on univariable testing were entered into a multivariable Cox proportional hazards model comparing them with time to ETV+CPC failure. Only corrected age $<1$ month (adjusted HR [aHR] 1.9, 95\% CI 1.0-3.6) and the post-IVH secondary to prematurity etiology (aHR 2.0, 95\% CI 1.1-3.6) were found to be independent predictors of ETV+CPC failure. Ventricle size, formally trained procedures, and the use of the flexible scope were not independently predictive (Table 3 ).

\section{Relationships Between Age and Etiology as They Pertain to ETV+CPC Failure}

Given that corrected age $(\mathrm{p}=0.078)$ and etiology ( $\mathrm{p}$ $=0.007$ ) appeared significant as categories, we further stratified each etiology by corrected age while examining the relationship with time to ETV+CPC failure (Fig. 4). For myelomeningocele, success rates at 1 year were $48 \%, 62 \%, 100 \%$, and $100 \%$ for age categories $<1$ month, $1-5$ months, 6-11 months, and $\geq 1$ year, respectively (Fig. 4A). For post-IVH secondary to prematurity, success rates at 1 year were $9 \%, 28 \%, 75 \%$, and $0 \%$ for corrected age categories $<1$ month, 1-5 months, 6-11 months, and $\geq 1$ year, respectively (Fig. 4B). For aqueductal stenosis, suc- cess rates at 1 year were $32 \%, 60 \%, 83 \%$, and $100 \%$ for age categories $<1$ month, $1-5$ months, $6-11$ months, and $\geq$ 1 year, respectively (Fig. 4C). For the heterogeneous "other" category, success rates at 1 year were $49 \%, 46 \%, 49 \%$, and $100 \%$ for age categories $<1$ month, $1-5$ months, $6-11$ months, and $\geq 1$ year, respectively (Fig. 4D).

\section{Effects of Formal Training on ETV+CPC Patient Selection and Technique}

Pediatric neurosurgeons with formal training at $\mathrm{CCHU}$ were more likely to offer ETV+CPC to younger children, especially to those $<1$ month of age $(\mathrm{p}=0.026)$ (Table 4). However, there were no differences in patient selection in regard to hydrocephalus etiology, comorbidities, or preoperative ventricle size associated with formal training. Training did significantly affect ETV+CPC surgical technique because formally trained procedures were longer $(\mathrm{p}$ $=0.03)$, more likely to use the flexible endoscope (94\% vs $42 \%, \mathrm{p}<0.001)$, more likely to report $>90 \%$ CPC $(91 \%$ vs $46 \%, p<0.001)$, and less likely to leave an EVD $(1 \%$ vs $17 \%, \mathrm{p}<0.001)$. There was no statistical difference in time to failure for formally trained ETV+CPC procedures versus formally untrained procedures $(\mathrm{p}=0.63$; see Table 3 ); however, in our cohort, $60 \%$ of the formally trained and $48 \%$ of the formally untrained procedures failed by 2 years. Furthermore, formally trained procedures were significantly more likely to be rescued with a repeat ETV as opposed to shunting ( $33 \%$ vs $10 \%, \mathrm{p}=0.01$ ) than formally untrained procedures (Table 4).

\section{Complications of ETV+CPC}

Intraoperative and postoperative complications of the ETV+CPC procedures are presented in Table 5 . We have data for $180(94 \%)$ infants in regard to inpatient complications and before discharge. We found a 3.9\% rate of moderate to severe intraoperative hemorrhage, a $1.7 \%$ rate of seizures, and a $3.4 \%$ CSF leak, of which only 1 case required return to surgery.

\section{Discussion}

To our knowledge, this multicenter study represents the largest North American investigation of ETV+CPC for the treatment of infant hydrocephalus. Throughout the 8 participating centers within the HCRN, we found an overall ETV + CPC success rate of $48 \%$ at 6 months and $44 \%$ at 2 years from 2006 through 2015. Univariable and multivariable Cox proportional hazards modeling found that corrected age and etiology were the only variables to predict time to ETV+CPC failure. Although formal training at the high-volume CCHU was associated with more extensive $\mathrm{CPC}$ and a willingness to offer ETV+CPC to younger infants, there was no benefit in terms of procedural success.

The Investigator Committee of the HCRN, through consensus, chose a success rate of $\geq 40 \%$ as a cutoff to identify specific subpopulations of infant hydrocephalus that may preferentially benefit from ETV+CPC. Using this criterion, we found that all infants with myelomeningocele, infants older than 1 month corrected age with aqueductal stenosis, and those older than 6 months corrected age with the post-IVH secondary to prematurity etiology may be 
TABLE 3. Comparing clinical and operative variables versus time to $E T V+C P C$ failure

\begin{tabular}{|c|c|c|c|c|}
\hline \multirow[b]{2}{*}{ Clinical or Operative Variable } & \multirow[b]{2}{*}{ Unadjusted HR w/ 95\% Cls } & \multicolumn{2}{|c|}{ Cox Proportional Hazards p Value } & \multirow[b]{2}{*}{ aHR w/ 95\% Cls } \\
\hline & & Univariable & Multivariable & \\
\hline \multicolumn{5}{|l|}{ Clinical variables } \\
\hline Corrected age & & 0.026 & 0.078 & \\
\hline$<1 \mathrm{mo}$ & $1.9(1.1-3.6)$ & & & $1.9(1.0-3.6)$ \\
\hline $1-5$ mos & $1.6(0.9-3.0)$ & & & $1.6(0.8-3.0)$ \\
\hline $6-11$ mos & Reference & & & Reference \\
\hline$\geq 1 \mathrm{yr}$ & $0.4(0.1-1.6)$ & & & $0.4(0.1-2.0)$ \\
\hline Male sex & $1.1(0.7-1.6)$ & 0.73 & - & - \\
\hline White race & $0.8(0.5-1.2)$ & 0.26 & - & - \\
\hline Collapsed etiology & & 0.001 & 0.007 & \\
\hline Post-IVH secondary to prematurity & $2.3(1.3-4.2)$ & & & $2.0(1.1-3.6)$ \\
\hline Myelomeningocele & $1.0(0.5-1.9)$ & & & $0.9(0.4-1.7)$ \\
\hline Aqueductal stenosis & Reference & & & Reference \\
\hline Other etiology & $1.1(0.6-2.0)$ & & & $1.1(0.6-2.0)$ \\
\hline$\geq 1$ comorbidity & $0.9(0.6-1.3)$ & 0.53 & - & - \\
\hline Head circumference \%ile & $1.0(0.9-1.0)$ & 0.75 & - & - \\
\hline FOR & $6.9(1.3-37.9)$ & 0.027 & 0.17 & $3.9(0.6-28.0)$ \\
\hline Concavity of floor of 3rd ventricle & $0.7(0.4-1.2)$ & 0.20 & - & - \\
\hline \multicolumn{5}{|l|}{ Operative variables } \\
\hline Conducted by trained surgeon & $1.4(0.9-2.1)$ & 0.089 & 0.63 & $1.1(0.7-1.8)$ \\
\hline Flexible scope & $1.5(0.9-2.4)$ & 0.095 & 0.43 & $1.3(0.7-2.2)$ \\
\hline$>90 \% \mathrm{CPC}$ & $1.0(0.6-1.5)$ & 0.94 & - & - \\
\hline Use of navigation & $0.9(0.6-1.3)$ & 0.43 & - & - \\
\hline Ballooning of floor of 3rd ventricle & $0.9(0.5-1.5)$ & 0.64 & - & - \\
\hline Residual prepontine membranes & $1.5(0.9-2.3)$ & 0.11 & - & - \\
\hline Endoscope guided through ventriculostomy & $1.2(0.5-2.7)$ & 0.66 & - & - \\
\hline Naked basilar view & $0.6(0.3-1.2)$ & 0.16 & - & - \\
\hline Size of ventriculostomy in mm & $0.9(0.8-1.1)$ & 0.37 & - & - \\
\hline EVD inserted & $1.3(0.7-2.6)$ & 0.47 & - & - \\
\hline
\end{tabular}

- = not applicable.

Boldface type indicates significant $(p<0.05)$ and near-significant $(p<0.10)$ values.

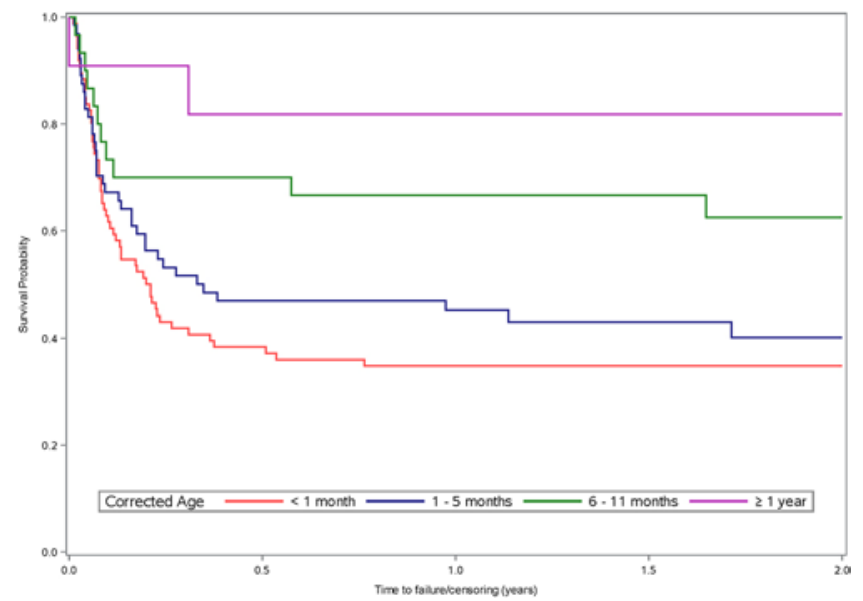

FIG. 2. A Kaplan-Meier plot of all ETV+CPCs conducted during the study, with the outcome of time to failure stratified by corrected age category: $<1$ month, $1-5$ months, $6-11$ months, and $\geq 1$ year. Figure is available in color online only.

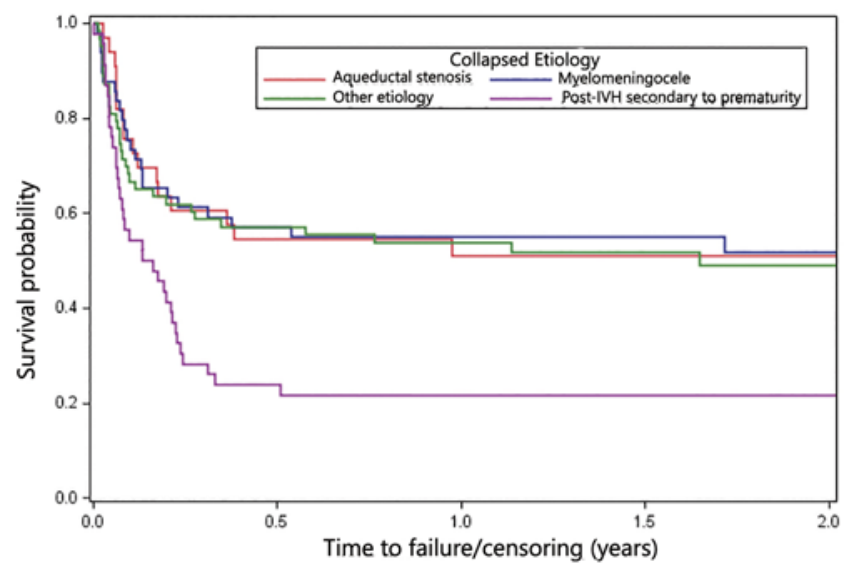

FIG. 3. A Kaplan-Meier plot of all ETV+CPCs conducted during the study, with the outcome of time to failure stratified by hydrocephalus cause category: post-IVH secondary to prematurity, myelomeningocele, aqueductal stenosis, and other causes. Figure is available in color online only. 

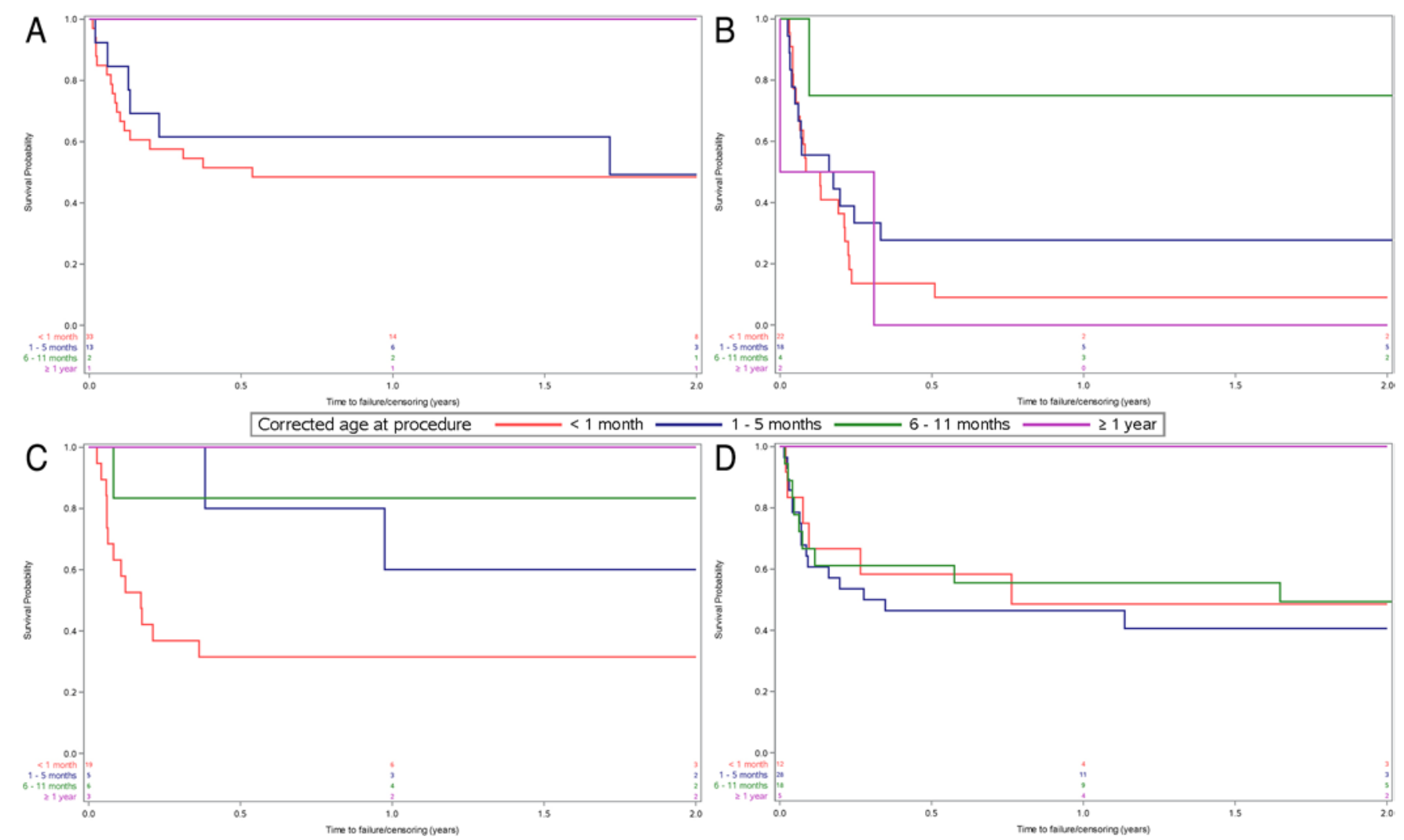

FIG. 4. Kaplan-Meier plots of subsamples of the ETV+CPC cohort each representing a single hydrocephalus cause, with the outcome of time to failure and stratified by corrected age category ( $<1$ month, 1-5 months, $6-11$ months, and $\geq 1$ year). A: Myelomeningocele. B: Post-IVH secondary to prematurity. C: Aqueductal stenosis. D: Other etiologies. Figure is available in color online only.

the best candidates in whom to consider ETV+CPC as a surgical option.

\section{Overall ETV+CPC Success Rate}

Our success rate in this study was $48 \%$ at 6 months and $44 \%$ at 2 years. This success is higher than the HCRN's own previous prospective study (representing patients from 2014 to 2016), in which we found a 36\% success rate at 6 months..$^{10}$ Both studies had very similar populations in terms of age and etiology, but Kulkarni et al. prospectively applied a stringent definition of failure after 2014, which the current study did not. This may be critically important considering the results of Dewan et al., in which the determination of failure was found to be complex and was frequently "made in the setting of discordant data." The current study's results are comparable to our previous multicenter retrospective study, which found a $52 \%$ success rate, but these patients were incorporated into the current study. ${ }^{8}$ In terms of other groups, our success rate was higher than that of Weil et al., ${ }^{23}$ who reported a $42 \%$ success at 6 months and $37 \%$ overall at a single center. One hypothesis for our marginally better success from this group might be the more prevalent use of the flexible scope versus the rigid scope. However, this study did not find the use of the flexible scope to be independently predictive of failure, and previous work has not found the rigid scope to be demonstrably inferior. ${ }^{18}$ Both Stone and
Warf ${ }^{16}$ in a single-center North American setting (57\% success at 1 year) and Warf ${ }^{19}$ in an African setting (66\% overall success) reported a significantly higher ETV+CPC success. This discrepancy may be due to patient selection or technical competence, because both of those reports represent results from the originator of and most experienced surgeon with ETV+CPC-Dr. Warf-who personally supervised the formal training described in this study.

\section{Age, Hydrocephalus Etiology, and Degree of CPC as Predictors of ETV+CPC Success}

Both age ${ }^{13}$ and etiology $y^{15,17}$ have long been cited as independent predictors of CSF diversion success, especially regarding CSF shunts. They are also both integral to ETV (without CPC) success and are included in the validated ETVSS.? Therefore, it should not be surprising that they were the dominant predictors of ETV+CPC success found in this study. However, it is interesting that other published predictors of ETV+CPC were not found to be significant in this study, which has a large and diverse sample. The degree of CPC (>90\% vs $\leq 90 \%$ ) has been found to be associated with ETV+CPC success ${ }^{12}$ in 2 previous HCRN studies - univariably in the HCRN's retrospective study ( $p$ $=0.05)^{8}$ and multivariably in Kulkarni et al. ${ }^{10}(\mathrm{p}=0.02)$. The difference might lie in either this study's higher power or the Kulkarni et al. study's more sophisticated and structured method of quantifying CPC. 
TABLE 4. Differences between "trained" and "untrained" procedures

\begin{tabular}{|c|c|c|c|}
\hline Variables & Untrained ETV+CPC, n = 76 & Trained ETV+CPC, N = 115 & Univariable Association ( $p$ value) \\
\hline \multicolumn{4}{|l|}{ Patient characteristics } \\
\hline Corrected age & & & \multirow[t]{5}{*}{$0.026^{*}$} \\
\hline$<1 \mathrm{mo}$ & $28(36.8)$ & $58(50.4)$ & \\
\hline $1-5$ mos & $26(34.2)$ & $38(33.0)$ & \\
\hline $6-11 \mathrm{mos}$ & $16(21.1)$ & $14(12.2)$ & \\
\hline$\geq 1 \mathrm{yr}$ & $6(7.9)$ & $5(4.3)$ & \\
\hline Collapsed etiology & & & \multirow[t]{5}{*}{$0.90 \dagger$} \\
\hline Post-IVH secondary to prematurity & $17(22.4)$ & $29(25.2)$ & \\
\hline Myelomeningocele & $19(25.0)$ & $30(26.1)$ & \\
\hline Aqueductal stenosis & $15(19.7)$ & $18(15.7)$ & \\
\hline Other etiology & $25(32.9)$ & $38(33.0)$ & \\
\hline Male sex & $48(63.2)$ & $77(67.0)$ & $0.64 \dagger$ \\
\hline$\geq 1 \mathrm{CCC}$ & $37(48.7)$ & $50(43.5)$ & $0.55 \dagger$ \\
\hline OFC \%ile, mean \pm SD & $84.0 \pm 28.4$ & $84.8 \pm 28.5$ & $0.87 \ddagger$ \\
\hline FOR, mean \pm SD & $0.60 \pm 0.12$ & $0.60 \pm 0.10$ & $0.74 \ddagger$ \\
\hline \multicolumn{4}{|l|}{ Procedural characteristics } \\
\hline Duration of op in mins, mean \pm SD & $98.6 \pm 42.6$ & $111.9 \pm 35.5$ & $0.030 \ddagger$ \\
\hline Use of navigation & $37(48.7)$ & $25(21.7)$ & $<0.001 \dagger$ \\
\hline Flexible scope & $32(42.1)$ & $108(93.9)$ & $<0.001 \dagger$ \\
\hline$>90 \%$ of $\mathrm{CPC}$ & $35(46.1)$ & $105(91.3)$ & $<0.001 \dagger$ \\
\hline Size of ventriculostomy in $\mathrm{mm}$, mean $\pm \mathrm{SD}$ & $4.9 \pm 1.4$ & $4.9 \pm 1.2$ & $0.84 \ddagger$ \\
\hline Residual prepontine membranes & $17(22.4)$ & $15(13.0)$ & $0.12 \dagger$ \\
\hline EVD inserted & $13(17.1)$ & $1(0.9)$ & $<0.001 \dagger$ \\
\hline Re-treatment modality after ETV+CPC failure $\S$ & & & $0.010 \dagger$ \\
\hline Repeat ETV & $4(10.3)$ & $23(33.3)$ & \\
\hline CSF shunt & $35(89.7)$ & $46(66.7)$ & \\
\hline
\end{tabular}

OFC $=$ occipital frontal circumference.

"Untrained" procedures refers to those done by neurosurgeons either who had never gone to CCHU or prior to their training at CURE; "trained" procedures refers to those done by neurosurgeons after training at CURE. Unless otherwise indicated, values are expressed as the number of patients (\%). Boldface type indicates significant values.

${ }^{*}$ Mantel-Haenszel chi-square test.

$\dagger$ Fisher's exact test.

$\ddagger$ Two-sided t-test with unpooled variance.

$\S$ Percentages are of those who had a successfully completed ETV+CPC procedure that eventually failed (i.e., was not abandoned).

\section{Identification of Specific Subpopulations of Infant Hydrocephalus for ETV+CPC}

As noted above, reported ETV+CPC success rates vary significantly, from $36 \%$ to $66 \%, 4,8,10,16,18,19,23$ perhaps indicating that patient selection may be confounding. This study was designed to cast the widest net over the HCRN's multicenter experience to detect subpopulations that may differentially benefit from ETV+CPC. Using a combination of age and etiology similar to that found within the ETVSS, ${ }^{7}$ we have generated several subpopulations with the hypothesis that they may specifically benefit from this procedure-including most infants with myelomeningocele, those $>1$ month corrected age with aqueductal stenosis, and the rare infants in the post-IVH secondary to prematurity subpopulation who require CSF diversion after 6 months corrected age. These findings may serve as general guidelines for future management and can help define the appropriate eligibility criteria for future randomized com- parisons of ETV+CPC and CSF shunting in the infant hydrocephalus population.

\section{Formal Training and ETV+CPC Success}

For this study, formal training was defined by the surgeon traveling and working at CCHU in Mbale, Uganda, which is the original and highest-volume center of excellence for ETV+CPC. We found that formal training did influence surgical technique, including longer surgery, less frequent use of navigation, more frequent use of the flexible endoscope, infrequent EVD usage, and more extensive CPC. However, these technical changes did not translate into improved ETV+CPC success. This discrepancy is probably explained by our finding that patient selection is the major driver of ETV+CPC success rather than specific technical idiosyncrasies or possibly by the fact that all of the involved surgeons were already very experienced at neuroendoscopy. It is important to note that formal train- 
TABLE 5. The incidence of ETV+CPC immediate and short-term complications

\begin{tabular}{|c|c|c|}
\hline Complication & $\begin{array}{c}\text { Immediate } \\
\text { Inpatient } \\
\text { Complications, } \\
n=180\end{array}$ & $\begin{array}{c}\text { Delayed } \\
\text { Outpatient } \\
\text { Complications, } \\
n=96\end{array}$ \\
\hline \multicolumn{3}{|l|}{ Surgical } \\
\hline Major arterial injury* & $0(0)$ & NA \\
\hline Hemorrhage during procedure* & & NA \\
\hline None & $111(61.7)$ & \\
\hline Mild; nonobstructive & $62(34.4)$ & \\
\hline Moderate; obstructive $<5$ mins & $6(3.3)$ & \\
\hline Severe; obstructive $\geq 5$ mins & $1(0.6)$ & \\
\hline \multicolumn{3}{|l|}{ Postop hemorrhage } \\
\hline $\mathrm{IVH}$ & $3(1.7)$ & $0(0)$ \\
\hline ICH/SDH/EDH & $0(0)$ & $0(0)$ \\
\hline New neurological deficit & $1(0.6)$ & $1(1.0)$ \\
\hline New seizure & $3(1.7)$ & $0(0)$ \\
\hline \multicolumn{3}{|l|}{ CSF leak } \\
\hline Minor; suture & $5(2.8)$ & $1(1.0)$ \\
\hline Major; return to OR & $1(0.6)$ & $1(1.0)$ \\
\hline Pseudomeningocele & $0(0)$ & $1(1.0)$ \\
\hline Subdural hygroma & $2(1.1)$ & $1(1.0)$ \\
\hline Wound infection & $0(0)$ & $1(1.0)$ \\
\hline Bacterial meningitis & $0(0)$ & $0(0)$ \\
\hline \multicolumn{3}{|l|}{ Medical } \\
\hline Hyponatremia & $2(1.1)$ & $0(0)$ \\
\hline Urinary tract infection & $3(1.7)$ & $0(0)$ \\
\hline Sepsis & $0(0)$ & $0(0)$ \\
\hline Pneumonia & $1(0.6)$ & $0(0)$ \\
\hline Cardiac arrest & $0(0)$ & $0(0)$ \\
\hline DVT/PE & $0(0)$ & $0(0)$ \\
\hline Pressure sores & $1(0.6)$ & $0(0)$ \\
\hline \multicolumn{3}{|c|}{$\begin{array}{l}\text { DVT = deep venous thrombosis; } E D H=\text { epidural hemorrhage; } N A=\text { not ap- } \\
\text { plicable; OR = operating room; } \mathrm{PE}=\text { pulmonary embolism; } \mathrm{SDH}=\text { subdural } \\
\text { hemorrhage. } \\
\text { Values are expressed as the number of patients (\%). } \\
\text { * Based on a total of } 191 \text { patients. }\end{array}$} \\
\hline
\end{tabular}

ing did significantly lead to more rescue ETVs after failed ETV+CPCs $(p=0.01)$, indicating that if the outcome of interest for patients is shunt freedom, our results and formal training might look more promising, as suggested by Stone and Warf. ${ }^{16}$

\section{Limitations of the Study}

The largest limitation of the study is that our definition of failure, besides death or immediate ETV+CPC abandonment, was that the decision about the need for a subsequent ETV or shunt was entirely left up to the treating surgeon and was open to subjectivity. Although the vast majority of previously published CSF diversion studies have used this definition of failure, generalizability between centers and surgeons cannot be guaranteed. Therefore, in response to this limitation, the HCRN (unfortunately after this study's completion) developed more objective criteria, which can be found in Appendix 2 of our subsequent prospective ETV+CPC study. ${ }^{10}$

Another limitation of this study is that we combined the results of a prospective cohort study nested within the HCRN's Core Data Project with those of our previously published retrospective cohort study. ${ }^{8}$ This decision was made in order to capture every ETV+CPC ever done at all of the 8 participating centers as well as to ensure inclusion of an unbiased sample of formally untrained procedures, including those done before a specific surgeon was trained at a later date. Another limitation is the subgroup analysis. Although this study represents the largest multicenter (predominantly prospective) study of ETV+CPC to our knowledge, we had the statistical power to conduct the univariable and multivariable analysis but not the subgroup analyses. Therefore, the reported subpopulations of potential benefit and failure for ETV+CPC should only be considered as hypothesis generating and require further validation.

\section{Conclusions}

This large, multicenter (predominantly prospective), North American cohort study demonstrated that young age and certain etiologies were independent predictors of ETV+CPC failure in the infant hydrocephalus population. Subpopulations combining specific age categories and etiologies were identified as potential targets that may preferentially derive benefit from ETV+CPC. These included most infants with myelomeningocele, those $>1$ month corrected age with aqueductal stenosis, and those $>6$ months corrected age with the post-IVH secondary to prematurity etiology. Although formal ETV+CPC training was associated with technical changes of practice, an increased degree of CPC, and changes in ETV+CPC failure management, this formal training was not found to be associated with improved ETV+CPC success.

\section{Acknowledgments}

The HCRN has been funded by the National Institute of Neurological Disorders and Stroke (NINDS, grant no. 1RC1NS068943-01), the Patient Centered Outcome Research Institute (PCORI, grant no. CER-1403-13857), the Gerber Foundation (reference no. 1692-3638), private philanthropy, and the Hydrocephalus Association. None of the sponsors participated in the design and conduct of this study; collection, management, analysis, and interpretation of the data; or preparation, review, or approval of this paper. Its contents are solely the responsibility of the authors and do not necessarily represent the official view of the sponsors.

We thank our colleagues for their past and ongoing support of the HCRN: D Brockmeyer, M Walker, R Bollo, S Cheshier, J Blount, J Johnston, B Rocque, L Ackacpo-Satchivi, J Oakes, P Dirks, J Rutka, M Taylor, D Curry, R Dauser, A Jea, S Lam, H Weiner, T Luerssen, R Ellenbogen, J Ojemann, A Lee, A Avellino, S Greene, E Tyler-Kabara, TS Park, M Smyth, N Tulipan, A Singhal, P Steinbok, D Cochrane, W Hader, C Gallagher, M Benour, E Kiehna, J G McComb, A Robison, A Alexander, M Handler, B O'Neill, C Wilkinson, L Governale, J Leonard, E Sribnick, E Ahn, A Cohen, M Groves, S Robinson.

In addition, our work would not be possible without the outstanding support of the dedicated personnel at each clinical site and the DCC. Special thanks go to Salim Ahmed for his help in paper preparation at the Calgary site as well as J Clawson, P 
Martello, N Tattersall, T Bach (Salt Lake City); A Arynchyna, A Bey (Birmingham); H Ashrafpour, M Lamberti-Pasculli, L O'Connor (Toronto); S Martinez, S Ryan (Houston); A Anderson, G Bowen (Seattle); K Diamond, A Luther (Pittsburgh); H Botteron, D Morales, M Gabir, D Berger, D Mercer (St. Louis); J Stoll, D Dawson, S Gannon (Nashville); A Cheong, R Hengel (British Columbia); A Loudermilk (Baltimore); N Rea, C Cook (Los Angeles); S Staulcup (Colorado); A Boczar (Columbus); and M Langley, V Wall, N Nunn, V Freimann, L Herrera, B Miller (Utah DCC).

We also acknowledge Dr. Ben Warf, Dr. Peter Ssenyonga, Dr. John Mugamba, and all of the staff, patients, and families at $\mathrm{CCHU}$ in Mbale, Uganda, for their collaboration and dedication to training the participating pediatric neurosurgeons with the $\mathrm{HCRN}$ for the ETV+CPC technique.

\section{Appendix: HCRN Members}

The HCRN currently consists of the following clinical centers and investigators: Primary Children's Hospital, University of Utah (J Kestle); Children's Hospital of Alabama, University of Alabama at Birmingham (C Rozzelle); Hospital for Sick Children, University of Toronto (J Drake, A Kulkarni); Texas Children's Hospital, Baylor College of Medicine (W Whitehead); Seattle Children's Hospital, University of Washington (S Browd, T Simon, J Hauptman); Children's Hospital of Pittsburgh, University of Pittsburgh (I Pollack); St. Louis Children's Hospital, Washington University in St. Louis (D Limbrick); Monroe Carell Jr. Children's Hospital at Vanderbilt, Vanderbilt University Medical Center (J Wellons, R Naftel, C Shannon); British Columbia Children's Hospital, University of British Columbia (M Tamber, P McDonald); Alberta Children's Hospital, University of Calgary (J Riva-Cambrin); The Johns Hopkins Hospital (E Jackson); Children's Hospital of Los Angeles (M Krieger); Children's Hospital Colorado (T Hankinson); Nationwide Children's Hospital (J Pindrik); HCRN DCC, Department of Pediatrics, University of Utah (R Holubkov).

\section{References}

1. Bankole OB, Ojo OA, Nnadi MN, Kanu OO, Olatosi JO: Early outcome of combined endoscopic third ventriculostomy and choroid plexus cauterization in childhood hydrocephalus. J Neurosurg Pediatr 15:524-528, 2015

2. Biluts H, Admasu AK: Outcome of endoscopic third ventriculostomy in pediatric patients at Zewditu Memorial Hospital, Ethiopia. World Neurosurg 92:360-365, 2016

3. Chamiraju P, Bhatia S, Sandberg DI, Ragheb J: Endoscopic third ventriculostomy and choroid plexus cauterization in posthemorrhagic hydrocephalus of prematurity. J Neurosurg Pediatr 13:433-439, 2014

4. Dewan MC, Lim J, Morgan CD, Gannon SR, Shannon CN, Wellons JC III, et al: Endoscopic third ventriculostomy with choroid plexus cauterization outcome: distinguishing success from failure. J Neurosurg Pediatr 25:655-662, 2016

5. Feudtner C, Christakis DA, Connell FA: Pediatric deaths attributable to complex chronic conditions: a population-based study of Washington State, 1980-1997. Pediatrics 106:205209, 2000

6. Kulkarni AV, Donnelly R, Mabbott DJ, Widjaja E: Relationship between ventricular size, white matter injury, and neurocognition in children with stable, treated hydrocephalus. J Neurosurg Pediatr 16:267-274, 2015

7. Kulkarni AV, Drake JM, Mallucci CL, Sgouros S, Roth J, Constantini S: Endoscopic third ventriculostomy in the treatment of childhood hydrocephalus. J Pediatr 155:254-259, 259.e1, 2009

8. Kulkarni AV, Riva-Cambrin J, Browd SR, Drake JM, Holubkov R, Kestle JR, et al: Endoscopic third ventriculostomy and choroid plexus cauterization in infants with hydrocephalus: a retrospective Hydrocephalus Clinical Research Network study. J Neurosurg Pediatr 14:224-229, 2014

9. Kulkarni AV, Riva-Cambrin J, Holubkov R, Browd SR, Cochrane DD, Drake JM, et al: Endoscopic third ventriculostomy in children: prospective, multicenter results from the Hydrocephalus Clinical Research Network. J Neurosurg Pediatr 18:423-429, 2016

10. Kulkarni AV, Riva-Cambrin J, Rozzelle CJ, Naftel RP, Alvey JS, Reeder RW, et al: Endoscopic third ventriculostomy and choroid plexus cauterization in infant hydrocephalus: a prospective study by the Hydrocephalus Clinical Research Network. J Neurosurg Pediatr 21:214-223, 2018

11. O'Hayon BB, Drake JM, Ossip MG, Tuli S, Clarke M: Frontal and occipital horn ratio: a linear estimate of ventricular size for multiple imaging modalities in pediatric hydrocephalus. Pediatr Neurosurg 29:245-249, 1998

12. Pindrik J, Rocque BG, Arynchyna AA, Johnston JM, Rozzelle CJ: Radiographic markers of clinical outcomes after endoscopic third ventriculostomy with choroid plexus cauterization: cerebrospinal fluid turbulence and choroid plexus visualization. J Neurosurg Pediatr 18:287-295, 2016

13. Riva-Cambrin J, Kestle JR, Holubkov R, Butler J, Kulkarni $\mathrm{AV}$, Drake J, et al: Risk factors for shunt malfunction in pediatric hydrocephalus: a multicenter prospective cohort study. J Neurosurg Pediatr 17:382-390, 2016

14. Simon TD, Butler J, Whitlock KB, Browd SR, Holubkov R, Kestle JR, et al: Risk factors for first cerebrospinal fluid shunt infection: findings from a multi-center prospective cohort study. J Pediatr 164:1462-1468, 1468.e1-1468.e2, 2014

15. Simon TD, Whitlock KB, Riva-Cambrin J, Kestle JR, Rosenfeld M, Dean JM, et al: Association of intraventricular hemorrhage secondary to prematurity with cerebrospinal fluid shunt surgery in the first year following initial shunt placement. J Neurosurg Pediatr 9:54-63, 2012

16. Stone SS, Warf BC: Combined endoscopic third ventriculostomy and choroid plexus cauterization as primary treatment for infant hydrocephalus: a prospective North American series. J Neurosurg Pediatr 14:439-446, 2014

17. Tuli S, Drake J, Lawless J, Wigg M, Lamberti-Pasculli M: Risk factors for repeated cerebrospinal shunt failures in pediatric patients with hydrocephalus. J Neurosurg 92:31-38, 2000

18. Wang S, Stone S, Weil AG, Fallah A, Warf BC, Ragheb J, et al: Comparative effectiveness of flexible versus rigid neuroendoscopy for endoscopic third ventriculostomy and choroid plexus cauterization: a propensity score-matched cohort and survival analysis. J Neurosurg Pediatr 19:585-591, 2017

19. Warf BC: Comparison of endoscopic third ventriculostomy alone and combined with choroid plexus cauterization in infants younger than 1 year of age: a prospective study in 550 African children. J Neurosurg 103 (6 Suppl):475-481, 2005

20. Warf BC: Congenital idiopathic hydrocephalus of infancy: the results of treatment by endoscopic third ventriculostomy with or without choroid plexus cauterization and suggestions for how it works. Childs Nerv Syst 29:935-940, 2013

21. Warf BC, Stagno V, Mugamba J: Encephalocele in Uganda: ethnic distinctions in lesion location, endoscopic management of hydrocephalus, and survival in 110 consecutive children. J Neurosurg Pediatr 7:88-93, 2011

22. Warf BC, Tracy S, Mugamba J: Long-term outcome for endoscopic third ventriculostomy alone or in combination with choroid plexus cauterization for congenital aqueductal stenosis in African infants. J Neurosurg Pediatr 10:108-111, 2012

23. Weil AG, Fallah A, Chamiraju P, Ragheb J, Bhatia S: Endoscopic third ventriculostomy and choroid plexus cauterization with a rigid neuroendoscope in infants with hydrocephalus. J Neurosurg Pediatr 17:163-173, 2016 
24. Weil AG, Westwick H, Wang S, Alotaibi NM, Elkaim L, Ibrahim GM, et al: Efficacy and safety of endoscopic third ventriculostomy and choroid plexus cauterization for infantile hydrocephalus: a systematic review and meta-analysis. Childs Nerv Syst 32:2119-2131, 2016

25. Zandian A, Haffner M, Johnson J, Rozzelle CJ, Tubbs RS, Loukas M: Endoscopic third ventriculostomy with/without choroid plexus cauterization for hydrocephalus due to hemorrhage, infection, Dandy-Walker malformation, and neural tube defect: a meta-analysis. Childs Nerv Syst 30:571-578, 2014

\section{Disclosures}

Dr. Limbrick received support from Microbot Medical, Inc., for a non-study-related clinical or research effort that he oversaw.

\section{Author Contributions}

Conception and design: all authors. Acquisition of data: all authors. Analysis and interpretation of data: all authors. Drafting the article: Riva-Cambrin, Kestle, Rozzelle, Naftel, Browd, Cochrane, Limbrick, Shannon, Simon, Tamber, Wellons,

Whitehead, Kulkarni. Critically revising the article: all authors. Reviewed submitted version of manuscript: all authors. Approved the final version of the manuscript on behalf of all authors: RivaCambrin. Statistical analysis: Riva-Cambrin, Alvey, Reeder, Holubkov. Administrative/technical/material support: Riva-Cambrin. Study supervision: Riva-Cambrin.

\section{Correspondence}

Jay Riva-Cambrin: Alberta Children's Hospital, Calgary, AB, Canada.jay.rivacambrin@ucalgary.ca. 